International Journal on Intelligent Electronic Systems, Vol.3, No.1, January 2009

\title{
CARRIER OVERLAPPING PWM METHODS FOR SINGLE PHASE FLYING CAPACITOR FIVE LEVEL INVERTER
}

\author{
Shanthi . $\mathbf{B}^{1}$, Natarajan .S.P ${ }^{2}$, Kayalvizhi . $\mathbf{R}^{3}$ \\ ${ }^{1}$ Centralised Instrumentation and Service Laboratory \\ ${ }^{2,3}$ Department of Instrumentation Engineering, Annamalai University \\ E-Mail : 'au_shan@yahoo.com, ${ }^{2}$ spn_annamalai@rediffmail.com
}

\begin{abstract}
This paper presents the comparison of carrier based PWM techniques (Carrier Overlapping Pulse Width Modulation (COPWM) and non-overlapping PWM techniques) for the Flying Capacitor Multi Level Inverter (FCMLI). Due to switch combination redundancies, there are certain degrees of freedom to generate the five level AC output voltage. This paper presents the use of Control Freedom Degree (CFD) combination. The effectiveness of the Pulse Width Modulation (PWM) strategies developed using CFD are demonstrated by simulation. The simulation results indicate that the use of CFD combination is an important clue to realize high performance multilevel inverters and the COPWM-A strategy developed exhibits reduced harmonics for moderate modulation indices and higher DC bus utilization than non-overlapping PWM methods.
\end{abstract}

Key words: Multilevel inverters, FCMLI, PWM, CFD, Sub-Harmonic PWM.

\section{INTRODUCTION}

Multilevel inverter has drawn tremendous interest in high power applications because it has many advantages: it can realize high voltage and high power output through the use of semiconductor switches without use of transformer and without dynamic voltage balance circuits. When the number of output levels increases, harmonics of the output voltage and current as well as Electro Magnetic Interference (EMI) decrease. Nabae et al [1] , Lai and Peng [2] and Carrara et al [3] investigated three PWM methods with different vertical and horizontal combinations leading to the quantification of their output harmonics. Multilevel PWM methods based on control degrees of freedom combination and their theoretical analysis are discussed by Yan Deng et al [4]. Anshuman Shukla et al [5] used capacitors called flying capacitors for clamping the voltage across the power semiconductor devices in FCMLI. The FCMLI is not as common but it has some distinct advantages over diode-clamped topology including the absence of clamping diodes and the ability to regulate the flying capacitor voltages through redundant state selection even if the number of voltage levels is greater than three. Unlike the output series H-bridge inverter, isolated voltage sources are not required. Yuan et al [6] discussed the self balancing of the clamping capacitor-voltages in the multilevel capacitor-clamping-inverter under sub-harmonic PWM. Considering these advantages, Meynard et al [7] discussed the basic concepts of FCMLI and many practical applications in industry. The FCMLI is increasingly used in many high power applications because it is easier to increase number of levels in this inverter than the diode clamped multilevel inverters. Lee et al [8] presented the carrier based PWM method for voltage balancing of FCMLI. Kang and Hyun [9] suggested a simple harmonic analysis method for multi carrier PWM techniques using output phase voltage in multilevel inverter.

Multilevel inverters are being considered for an increasing number of applications due to their high power capability associated with lower output harmonics and lower commutation losses. Multilevel inverters have become an effective and practical solution for increasing power and reducing harmonics of AC load. Fig.1 shows structure of a single phase five level FCMLI. The switches are arranged in pairs called the commutation cell. The switches of a commutation cell should be in a complementary state, that is one on and the other off. Four switching pairs must be connected in series between DC input and load. The circuit includes three flying capacitors C3, C4 and C5 which are charged to different voltage levels. By changing the switching states, the capacitors and the DC source are connected in different ways and produce various load voltages. The load voltage can be determined for all combination of switching signals. Typical switch combinations for obtaining different output voltage levels are shown in Table 1 where ' + ' denotes charging and '-' denotes discharging of capacitors while ' $\mathrm{NC}$ ' indicates neither charging nor discharging.

The gate signals for the chosen five level FCMLI are developed using MATLAB-SIMULINK. 


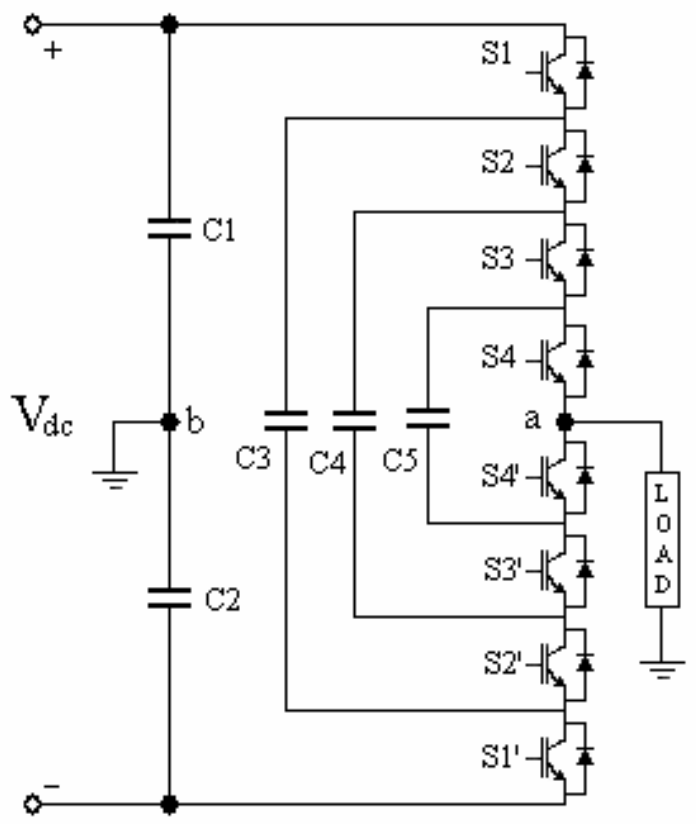

Fig. 1. Five level FCMLI

The gate signal generator model developed is tested for various values of modulation index. The results of the simulation study are presented in this work in the form of the PWM outputs of the chosen multilevel inverter. The simulation results of various PWM techniques used are compared and evaluated.

Table 1 Switching scheme for single phase five level FCMLI

\begin{tabular}{|c|c|c|c|c|c|c|c|}
\hline S1 & S2 & S3 & S4 & $\mathrm{C} 3$ & $\mathrm{C} 4$ & $\mathrm{C5}$ & $V_{a b}$ \\
\hline 1 & 1 & 1 & 1 & $\mathrm{NC}$ & $\mathrm{NC}$ & $\mathrm{NC}$ & $+\mathrm{V}_{d c} / 2$ \\
\hline 1 & 1 & 1 & 0 & $\mathrm{NC}$ & $\mathrm{NC}$ & + & \multirow{4}{*}{$+\mathrm{V}_{\mathrm{dd}} / 4$} \\
\hline 1 & 1 & 0 & 1 & $\mathrm{NC}$ & + & - & \\
\hline 1 & 0 & 1 & 1 & + & - & $\mathrm{NC}$ & \\
\hline 0 & 1 & 1 & 1 & - & $\mathrm{NC}$ & $\mathrm{NC}$ & \\
\hline 0 & 0 & 1 & 1 & $\mathrm{NC}$ & - & $\mathrm{NC}$ & \multirow{6}{*}{0} \\
\hline 0 & 1 & 0 & 1 & - & + & - & \\
\hline 0 & 1 & 1 & 0 & - & $\mathrm{NC}$ & + & \\
\hline 1 & 0 & 0 & 1 & + & $\mathrm{NC}$ & - & \\
\hline 1 & 0 & 1 & 0 & + & - & + & \\
\hline 1 & 1 & 0 & 0 & $\mathrm{NC}$ & + & $\mathrm{NC}$ & \\
\hline 1 & 0 & 0 & 0 & + & $\mathrm{NC}$ & $\mathrm{NC}$ & \multirow{4}{*}{$-V_{d c} / 4$} \\
\hline 0 & 1 & 0 & 0 & - & + & $\mathrm{NC}$ & \\
\hline 0 & 0 & 1 & 0 & $\mathrm{NC}$ & - & + & \\
\hline 0 & 0 & 0 & 1 & $\mathrm{NC}$ & $\mathrm{NC}$ & - & \\
\hline 0 & 0 & 0 & 0 & $\mathrm{NC}$ & $\mathrm{NC}$ & $\mathrm{NC}$ & $-V_{d c} / 2$ \\
\hline
\end{tabular}

\section{MODULATION STRATEGIES FOR MULTILEVEL INVERTERS}

A number of modulation strategies are used in multilevel power conversion applications. They can generally be classified into three categories:

- Multistep, staircase or fundamental frequency switching strategies

- Space Vector PWM strategies

- Carrier based PWM strategies

Of all the PWM methods for flying capacitor multilevel inverter, carrier based PWM methods and space vector methods are often used but when the number of output level is more than five, the space vector method will be very complicated with the increase of switching states. So the carrier based PWM method is preferred under this condition in multilevel inverters. This paper focuses on carrier based PWM techniques which have been extended for use in multilevel inverter topologies by using multiple carriers.

Multilevel carrier based PWM methods have more than one carrier that can be triangular waves or saw tooth waves and so on. As far as the particular carrier signals are concerned, there are multiple CFD including frequency, amplitude, phase of each carrier and offsets between carriers. The modulating/ reference wave of multilevel carrier based PWM method can be sinusoidal or trapezoidal. As far as the particular reference wave is concerned, there is also multiple CFD including frequency, amplitude, phase angle of the reference wave and as in three phase circuits, the injected zero sequence signal to the reference wave. Therefore, multilevel carrier based PWM methods can offer multiple CFD. These CFD combinations combined with the basic topology of multilevel inverters can produce many multilevel carrier based PWM methods.

\section{CARRIER BASED PWM METHODS BASED ON CFD COMBINATION}

This paper presents three COPWM methods that utilize the CFD of vertical offsets among carriers. They are: COPWM-A, COPWM-B, COPWM-C. The above three methods are simulated in this work. For comparison purposes, a non-overlapping Sub-Harmonic PWM (SHPWM) method is also presented in this work.

For an m-level inverter using carrier overlapping technique, $m-1$ carriers with the same frequency $f_{c}$ and same peak-to-peak amplitude $A_{c}$ are disposed such that the bands they occupy overlap each other; the overlapping 
vertical distance between each carrier is $A_{c} / 2$. The reference waveform has amplitude of $A_{m}$ and frequency of $f_{m}$ and it is centered in the middle of the carrier signals. The reference wave is continuously compared with each of the carrier signals. If the reference wave is more than a carrier signal, then the active devices corresponding to that carrier are switched on. Otherwise, the devices switch off. The amplitude modulation index $m_{a}$ and the frequency ratio $m_{f}$ are defined in the carrier overlapping method as follows:

$$
\begin{aligned}
& m_{a}=A_{m} /\left((m / 4)^{*} A_{c}\right) \\
& m_{f}=f_{c} / f_{m}
\end{aligned}
$$

In this paper, $m_{f}=21, A_{c}=1.6$ and $m_{a}$ is varied from 0.5 to 1 .

\section{A. COPWM-A strategy}

The vertical offset of carriers for five level inverter with COPWM-A method is illustrated in Fig.2. It can be seen that the four carriers are overlapped with other and the reference sine wave is placed at the middle of the four carriers.

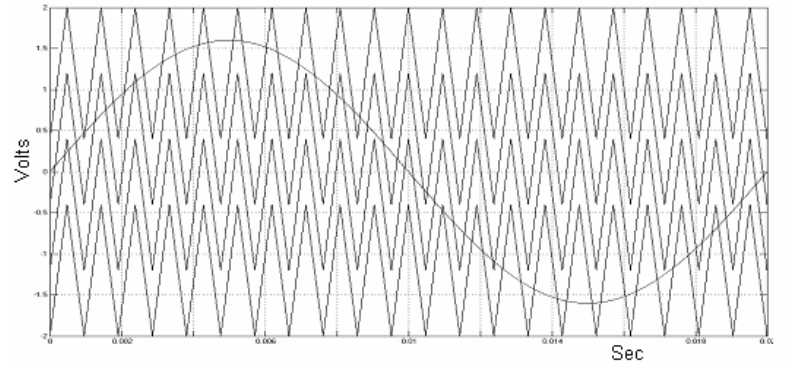

Fig. 2. Carrier arrangement for COPWM-A strategy

\section{B. COPWM-B strategy}

Carriers for five level inverter with COPWM-B method are shown in Fig.3. It can be seen that they are divided equally into two groups according to the positive/negative average levels. In this type the two groups are opposite in phase with each other while keeping in phase within the group.

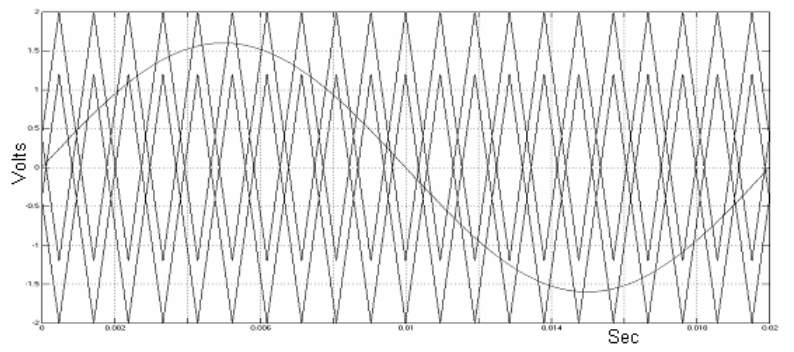

Fig. 3. Carrier arrangement for COPWM-B strategy C. COPWM-C strategy

Carriers for five level inverter with COPWM-C method are shown in Fig.4. In this pattern, the carriers invert their phase in turns from the previous one. It may be identified as PWM with amplitude-overlapped and neighbouring-phaseinterleaved carriers. Actually, pattern $B$ and $C$ can be looked on as a second control freedom change besides offsets in vertical: the carriers' have horizontal phase shift from patternA.

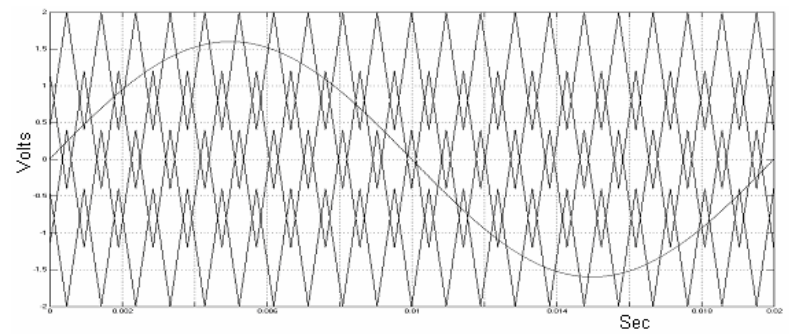

Fig. 4. Carrier arrangement for COPWM-C strategy

\section{SHPWM strategy}

The principle of the SHPWM method is to use several triangular carriers with one modulation wave. For an $\mathrm{m}$-level inverter, $\mathrm{m}$-I triangular carriers of the same frequency $\mathrm{f}_{\mathrm{c}}$ and the same peak-to-peak amplitude $A_{c}$ are disposed so that the bands they occupy are contiguous. The zero reference is placed in the middle of the carrier set. Carrier arrangement for five level SHPWM is shown in Fig. $5 . \mathrm{m}_{\mathrm{a}}$ for this method is defined as

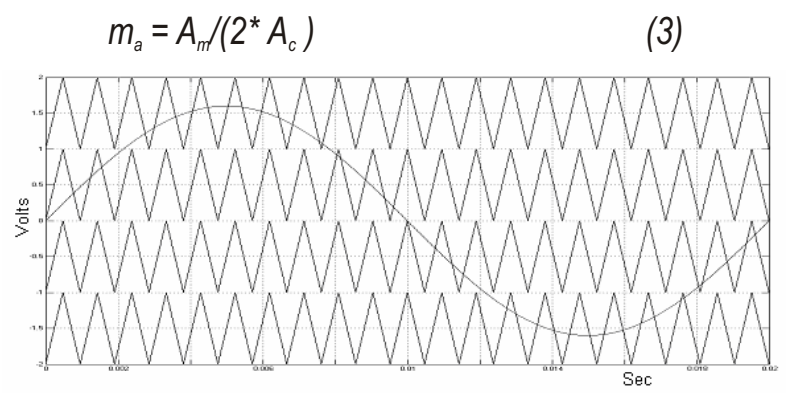

Fig. 5. Carrier arrangement for SHPWM strategy

\section{SIMULATION RESULTS}

The flying capacitor five level inverter is modelled in SIMULINK using power system block set. Switching signals for flying capacitor multilevel inverter using SHPWM and COPWM techniques are simulated.

Simulations are performed for different values of $m_{a}$ ranging from $0.5-1$ and the corresponding $\%$ THD are measured using the FFT block and their values are shown in Table 2. Next table displays the $V_{\text {rms }}$ of inverter output for different modulation indices. Figs.6-13 show the simulated output of FCMLI with above strategies but for only one sample value of $m_{a}=0.8$. 
Fig.6 displays the five level output voltage generated by COPWM-A switching strategy and its FFT plot is shown in Fig.7. Fig.8 shows the five level output voltage generated by COPWM-B switching strategy and its FFT plot is shown in Fig.9. Fig.10 shows the five level output voltage generated by COPWM-C switching strategy and its FFT plot is shown in Fig.11. Fig.12 shows the five level output voltage generated by SHPWM switching strategy and its FFT plot is shown in Fig.13. Fig.14 shows a graphical comparison of \%THD in various strategies for different modulation indices. The following parameter values are used for simulation: $V_{D C}=400 \mathrm{~V}$ and $\mathrm{R}(\mathrm{load})=50 \mathrm{ohms}$.

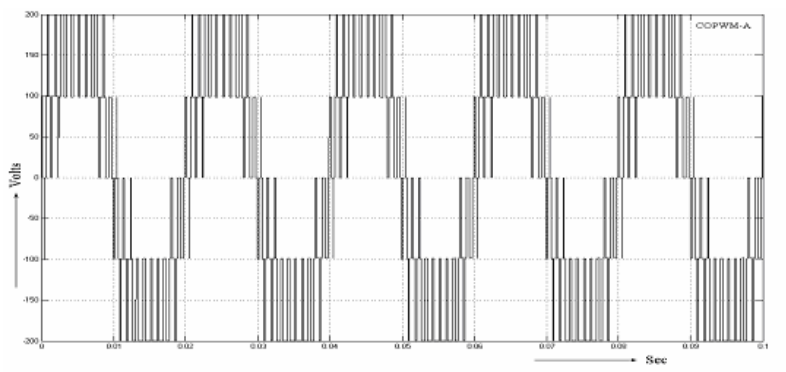

Fig. 6. Output voltage generated by COPWM-A strategy

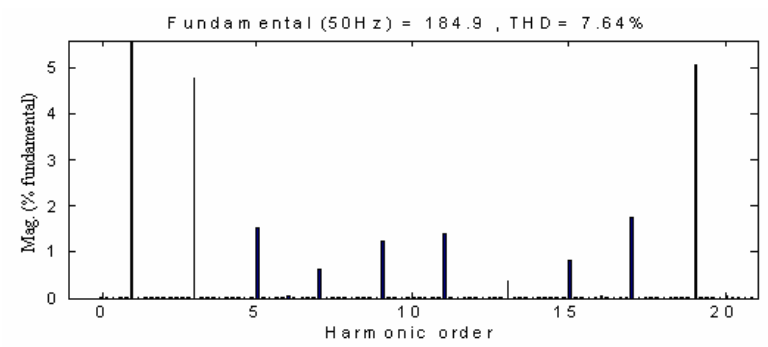

Fig. 7. FFT plot for COPWM-A strategy

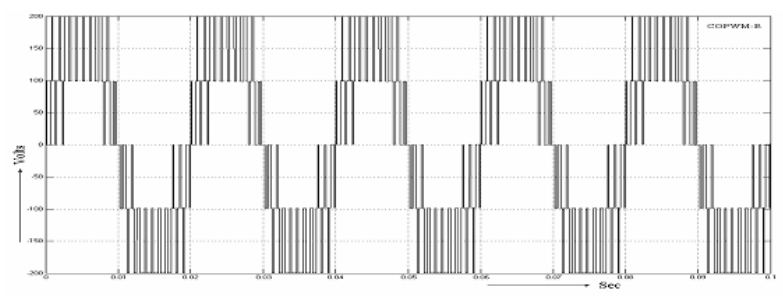

Fig. 8. Output voltage generated by COPWM-B strategy

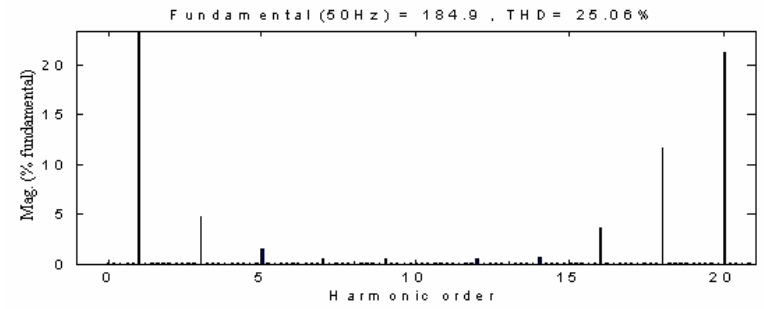

Fig. 9. FFT plot for COPWM-B strategy

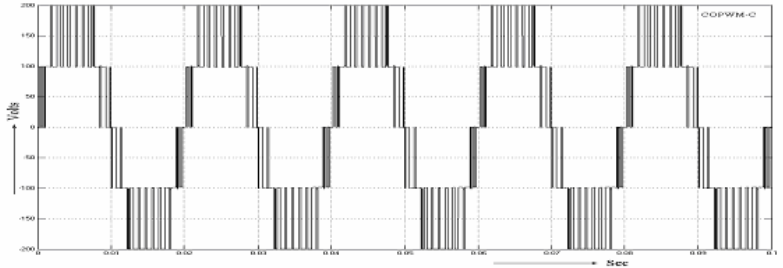

Fig. 10. Output voltage generated by COPWM-C strategy

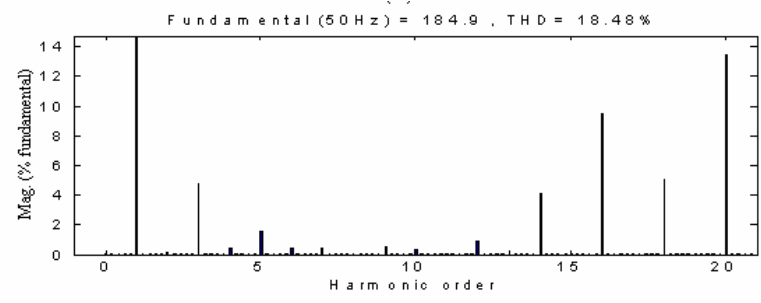

Fig. 11. FFT plot for COPWM-C strategy

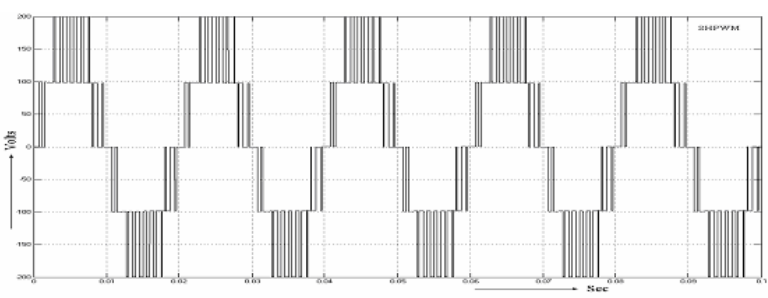

Fig. 12. Output voltage generated by SHPWM strategy

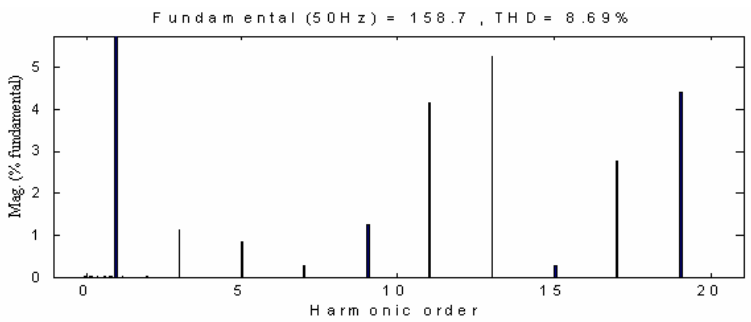

Fig. 13. FFT plot for SHPWM strategy

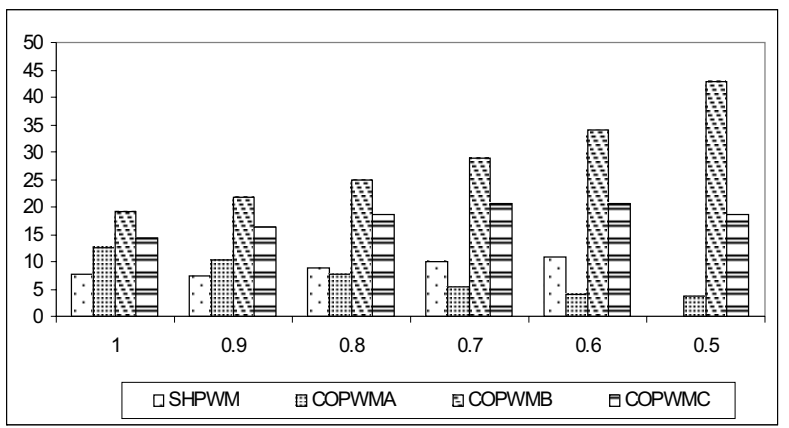

Fig. 14. \% THD Vs modulation index $\left(m_{a}\right)$ 
Table $2 \%$ THD for different modulation indices

\begin{tabular}{|c|c|c|}
\hline$m_{a}$ & $\begin{array}{c}\text { SHPWM } \\
\text { (Volts) }\end{array}$ & COPWM (Volts) \\
\hline 1.0 & 140.9 & 151.3 \\
\hline 0.9 & 127 & 141.3 \\
\hline 0.8 & 112 & 130.4 \\
\hline 0.7 & 98 & 119 \\
\hline 0.6 & 83.11 & 106 \\
\hline 0.5 & -- & 88 \\
\hline
\end{tabular}

Table 3 RMS output voltage for different modulation indices

\begin{tabular}{|c|c|c|c|c|}
\hline $\mathrm{m}_{\mathrm{a}}$ & SHPWM & $\begin{array}{c}\text { COPWM- } \\
\text { A }\end{array}$ & $\begin{array}{c}\text { COPWM- } \\
\text { B }\end{array}$ & $\begin{array}{c}\text { COPWM- } \\
\text { C }\end{array}$ \\
\hline 1.0 & 7.8 & 12.7 & 19.17 & 14.33 \\
\hline 0.9 & 7.49 & 10.2 & 21.7 & 16.2 \\
\hline 0.8 & 8.69 & 7.64 & 25.06 & 18.48 \\
\hline 0.7 & 9.99 & 5.5 & 28.77 & 20.52 \\
\hline 0.6 & 10.96 & 4.1 & 33.9 & 20.52 \\
\hline 0.5 & -- & 3.8 & 42.76 & 18.7 \\
\hline
\end{tabular}

\section{CONCLUSION}

In this paper, CFD based PWM strategies for chosen FCMLI have been presented. The COPWM-A method provides lower THD than the other methods for moderate $m_{a}$ whereas for high $m_{a}(0.9)$, the SHPWM method provides better performance (Table 2). COPWM method provides high DC bus utilization as in Table 3 .

\section{REFERENCES}

[1] A.Nabae, I.Takahashi and H.Akagi, Sept/Oct. 1981. "A new neutral-point clamped PWM inverter", IEEE Trans. Ind. Applicat., vol. IA-17, pp. 518-523.

[2] J.S.Lai and F.Z.Peng, May/June 1996. "Multilevel converters-A new breed of power converters", IEEE Trans. Ind. Applicat., vol. 32, pp. 509-517.

[3] G.Carrara, S.Gardella, M.Marchesoni, R.Salutari and G.Sciutto, July 1992. "A new multilevel PWM method: A theoretical analysis", IEEE Trans.Power Electron, vol. 7, pp. 497-505.

[4] Yan Deng, Hongyan Wang, Chao Zhang, Lei Hu and Xiangning He, 2005. "Multilevel PWM methods based on control degrees of freedom combination and its theoretical analysis", IEEE IAS 2005 Conference record no.: 0-7803-9208-6/05, pp. 1692-1699.

[5] Anshuman Shukla, Arindam Ghosh and Avinash Joshi, January 2007. "Hysteresis current control operation of flying capacitor multilevel inverter and its application in shunt compensation of distribution systems", IEEE Trans. Power Delivery, vol.22, no.1, pp. 396-405.

[6] X.Yuan, H.Stemmler and I.Barbi, March 2001. "Selfbalancing of the clamping capacitor-voltages in the multilevel capacitor-clamping-inverter under subharmonic PWM modulation", IEEE Trans. Power Electron., vol. 16, no. 2, pp. 256-263

[7] T.A.Meynard, H.Foch, P.Thomas, J.Courault, R.Jakob and M.Nahrstaedt, October 2002. "Multicell converters: basic concepts and industry applications", IEEE Trans. Ind. Electron, vol. 49, no. 5, pp. 955-964.

[8] S.G.Lee, F.W.Kang, Y.H.Lee and D.S.Hyun, 2001. "The carrier-based PWM method for voltage balancing of flying capacitor multilevel inverter", IEEE Power Electron. Spec. Conf. Rec., vol. 1, pp. 126-131.

[9] D.W.Kang and D.S.Hyun, April 2005. "Simple harmonic analysis method for multi-carrier PWM techniques using output phase voltage in multi-level inverter", IEE Proc.-Electr. Power Appl., vol. 152, no. 2, pp.157-165.

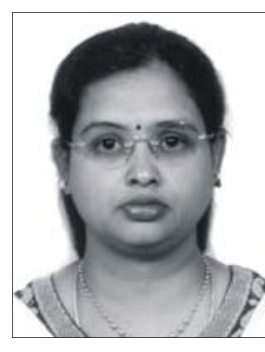

B. Shanthi Obtained her B.E. in Electronics and Instrumentation and M.Tech. in Instrument Technology from Annamalai University and Indian Institute of Science, Bangalore in 1991 and 1998 respectively. She is presently a Reader in Centralised Instrumentation and Service Laboratory of Annamalai University where she has put in a total service of 17 years since 1992. She is currently pursuing her $\mathrm{PhD}$ in the Department of Instrumentation Engg. on embedded control of single phase inverters. Her research papers (5) have been presented in various/IEEE international/national conferences. She has 1 publication in national and 3 in International International Journals. Her areas of interest are modelling, simulation and intelligent control for inverters. 